\title{
A Brief Account on the Significance of the Muoous Membrane. Sense.
}

\author{
By
}

\author{
Tamao Saito, M. D. \\ Professor in Psychiatry.
}

Little has been noticed of the significance of the mucous membrane sense, until in recent years when physiological bearings of the involuntary nervous system was brought into relative clearness by Schäfer, Langley, Sherrington and others. Although this sense is less differentiated than other nervous functions of the animal kingdom, it consists of a complex of similer senses : sense of pressure, sense of temperature and other senses. And as elementary is its character, its importance in our every day life should not be passed unheeded. Such instances may be seen in the oesophageal and rectal senses.

The oesophagus and rectum stand in a peculiar position in regard to the manner of innervation as compared with rest of the alimentary tract. As to the oesophagus, its unstriped muscles from larynx downward to the incisura cardiaca is innervated not by the sympathetic, but exclusively by the pneumogastric nerve. This region is, therefore, devoid of the sympathetic contral of the thoracico-lumbar ontflow of Gaskell. (1)

The afferent fibers from this region run in the pneumogastric nerve to the nerve cells of the vagel ganglion and connect further with the intercalate nucleus of Staderini, (Kidd (2)) the mesial part of the dorsal nucleus of the vagel stem: A reflex path starts from the latter nucleus to run the vegal stem downward and terminates on the efferent end neuron in the oesophageal walls. This neuron is represented by a series of cells of a nerve plexus lying on the circular muscle layer instead of dying between the circular and longitudinal muscle layers as in the rest of the alimentary tract.

The afferent fibers of the pelvic nerve, the main stem of the sacral outflow of Gaskell, run in the posterior root of the 2nd and 3 rd sacral segment, the ariginal nerve cells lying in the segmental root ganglia of the sacral cord. These Gers communicate with the intercalate neurons in the lateral horn of the same 
height. The latter neurons send connector fibers to the anterior root and further to the ramus communicans albus, and terminate in the rectal plexus. As this plexus can be regarded homologous to 'Auerbach's plexus in the innervation areas of the splanchnic nerve, there is an apparent analogy. between this and the submucous plexus of the oesophagus at the other extermity of the gut. In both cases the plexuses are found upon the surface layer instead of between the circular and longitudinal muscle layers.

Kalischer (3) has shown, in the musculature of the bladder walls, that the fine structure of muscle fibers supplied by the hypogastric nerve (sympathetic lumbar outflow) differs from that of the muscle fibers innervated by the pelvic nerve (sacral outflow). It appears then quite rational, to classify the involuntary muscls, as Kalischer did, into the vasordermal (supplied by the splanchnic nerve) and endodermal musculature (supplied by the bulbo-sacral outflow).

The anal extermity of this region ends now in the internal sphincter ani which is innervated by a branch of the hypogastric nerve, i. e., by the thoracicolumbar outflow (Langley and Anderson (4)). In other words, the sympathetic vasordermal musculature has invaded the endodermal musculture to form the outermost sphincter of the alimentary tract. These conditions can be compared with the fact that the oesophageal region begins orally from the laryngeal sphincter supplied by the 7 th, 9th and 12th cranial nerves, i. e., the mesosomatic group of the bulbar outflow (Gaskell (1)).

Further characteristic of the bulbo-sacral outflow is to be found in its reaction to a certain chemical substance. Dale (5) has proven that acetyl-choline; when injected intravenously in minute doses, produces the same effects as stimulation of the bulbo-sacral connector fibers. This is an analogous finding, as adrenalin injected intravenously in minute doses produces the same effects as stimulation of the thoracico-lumbar connector fibers.

Thus these two sections of the alimentary tract, the oesophagus and rectum, claim a special position in the anatomo-physiological as well as pharmaco-diagnostic respect.

Let us now consider for a while the physiological and psychological aspects. A bolus introduced in the oesophagus causes, by virtue of the submucous plexus (Magnus (6)), the contraction of the involuntary muscles of the walls just above it and relaxation of the parts below - peristaltic movernent. This movement is 
transmitted through the afferent fibers to report the sense of pressure, sense of temperature and several others centralward; its physiological effect being the oesophageal sense and its psychological effect the primary "Auftauchen" of consciousness of "being safely fed" and secondary feeling of contention and security.

Similar, if not the same, feeling is experienced accompanying the rectal sense as a faecal mass passes downward through that section of the gut. Both senses are so deeply rooted phylogenetically in the animal kingdom and have much to do with the vegetative functions necessary to sustain life.

These senses under consideration provide, therefore, the chief source of consciousness of welfare of our existence. And one will now have clear conception as to why the effect of such a feeling in our daily life should not be overlooked nor unduly underestimated.

This fact seems to us, to offer an important significance in connection with the medical practice.

One can only too easily imagine how profoundly the whole mood of a patient be effected when he is suffering, for instance, from cancer or stricture of either one of both organs. For every clinician it should be a matter of vital necessity always to keep in mind the importance of the mucous membrane sense, even when the present illness has apparently nothing to do with it. For it must certainly be soothing for sick people to feel the passage of nourishment and excrement just smooth and secure, as it is for healthy people.

Finally, it is noteworthy to mention the perverse sensation of the mucous membrane manifested, in regard to the oesophageal sense, in certain hysteric vomiting and rumination and, in regard to the rectal sense, in passive pederastia and rectal masturbation. It will, however, be superfluous to say that in these cases the essential morbid impulses occur chiefly in the highest station of the nervous system, i. e., the cerebral cortex. (Nov. 25, 1923).

\section{References.}

1) Gaskell, W. H., The involuntary nervous system. 1916.

2) Kidd, L. J., The nucleus intercalatus of Staderini. Review of Neurology and Psychiatry, 1914.

3) Kalischer, O., Dic Urogenital-Musculatur des Dammes. 1900.

4) Langley, J. N. and Anderson, H. K., Position of the nerve cells on the course of the efferent nerve fibers. Journal of Physiology, XIX, 1895. 
5). Dale, H. H., The occurrence in ergot and action of andycholine. Journal of Physiglogy, XLVLII. 1914.

6) Magnus, R. and Langley, J. N., Some observations on the movements of the intestine before and afier degenexative section of the mesenteric nerve. Journal of Physiology, XXXIII, 1905. 